\title{
Tiempo de desescalada y nueva normalidad. Una oportunidad para replantear los tiempos escolares situando al alumnado en el centro
}

\author{
Daniel Gabaldón Estevan ${ }^{1}$
}

El encierro generalizado de la población que ha provocado la crisis sanitaria derivada del COVID-19 ha tenido consecuencias especialmente radicales para la población infantil y juvenil que ha visto cómo su vida cotidiana ha dado un vuelco. Así, durante semanas lo único que ha permanecido a flote ha sido la vida en familia en el hogar, el contacto ocasional on-line con la familia extensa y amistades, y especialmente aquellas actividades formativas y extraescolares que han sido capaces de reinventarse, con mayor o menor fortuna, como actividades en línea. Desgraciadamente tardaremos tiempo en conocer con más detalle las consecuencias que este encierro ha supuesto en la vida de niñas y niños. Desde privaciones de las que es más fácil recuperarse, como el juego con iguales en espacios abiertos, hasta los abusos que dejan secuelas para toda la vida, como los delitos contra la libertad e indemnidad sexual ${ }^{2}$, pasando por las diferencias educativas que este paso a la docencia en línea pone aún más de manifiesto. Y es que en el ámbito escolar esta crisis ha provocado la repentina migración de la enseñanza presencial a la enseñanza a distancia a todos los niveles, pre, post y obligatorio, contando con la formación y los recursos necesarios para ello, o sin ellos. Pero la resolución y salida de esta crisis plantea también una oportunidad para replantearnos algunas mejoras también en el ámbito educativo. En este trabajo se revisan las evidencias respecto a la dimensión temporal en la organización escolar y se presentan siete recomendaciones a modo de llamamiento a las autoridades y a la comunidad educativa a reconsiderar los tiempos escolares en un contexto de cambio como el que vivimos y ante una inminente reforma de la legislación educativa.

\section{Dar el curso por terminado}

El curso escolar 2019-20 podía haberse darse por acabado para el grueso del alumnado de las etapas pre-obligatorias y obligatorias dado que la transición a la educación en línea en combinación con la brecha digital solo puede incrementar los niveles de desigualdad existentes. En la etapa de Educación Infantil ${ }^{3}$, al tratarse de una etapa pre-obligatoria de escolarización voluntaria, no debería generar ningún problema dar el curso académico por terminado si las autoridades sanitarias recomendaban la extensión del confinamiento. Lo mismo sucede con el alumnado de la etapa obligatoria (primaria y ESO) en tanto que un trimestre sobre un periodo de escolarización de diez años, que es lo que dura la enseñanza obligatoria en España, no debería suponer una pérdida insalvable en caso de no poder volver a las aulas hasta septiembre. Otra cuestión es la función de guardia y custodia en particular para el alumnado de familias en las que los progenitores trabajan de manera presencial y más aún si estos trabajan en la denominada primera línea contra el virus (personal sanitario, limpieza, etc.). En estas situaciones se debería articular soluciones que primen la seguridad y el bienestar de niñas y niños. Para las etapas post-obligatorias debería primar la adquisición de los conocimientos y competencias de que es garante el título, y por tanto deberían articularse las medidas necesarias para que se obtuvieran bien a distancia este curso, bien de manera presencial este curso o el próximo en función de lo que fuese posible y razonable.

\section{Reincorporación por necesidades (no por edades)}

La vuelta a las aulas, cuando sea posible iniciarla, no debería plantearse por cursos o niveles educativos sino que debería planificarse en función de las propias necesidades del alumnado. Es urgente recuperar primero a aquel alum-

\footnotetext{
Universitat de València.

E-mail: Daniel.Gabaldon@uv.es

http://www.juecesdemocracia.es/2020/04/10/la-comision-penal-ijpd-ante-la-necesidad-reforzar-la-prevencion-del-abuso-infantil-estado-alarma/

La educación infantil comprende el periodo hasta los 6 años de edad y no solo el primer ciclo (0-2 años) a pesar de que buena parte de la ciudadanía asocie gratuidad con obligatoriedad y piense erróneamente que la escolarización obligatoria se inicia a los 3 años (Gabaldón-Estevan y Taht, 2019).
} 
nado que ha sufrido una desconexión mayor por razón de la brecha digital asociada bien a la desigualdad en el acceso, generalmente por cuestiones económicas y de infraestructura como conexión a internet, limitación de datos o de equipamientos, pero también por bajo capital cultural en el seno familiar (escasa o nula alfabetización digital) o por falta de apoyo efectivo en el hogar o desde la escuela. Las medidas que plantean una incorporación simultánea por curso asumen erróneamente que todo el alumnado está en una misma posición e ignoran que una parte de ese alumnado requiere mayor atención. Una re-incorporación desigual facilitaría además cumplir con las medidas de distanciamiento que recomiendan las autoridades sanitarias al reducir la afluencia de alumnado al centro. En cualquier caso, permitiría al profesorado modular la afluencia del alumnado en función de sus necesidades educativas (más o menos días de asistencia al centro en función de las necesidades y las restricciones) y complementar la supervisión con sesiones on-line para el alumnado con menos carencias y mayores recursos y apoyo en casa. Este modelo de atención diferenciada, transformándose en apoyo en el aula y el refuerzo en el centro fuera de las horas ordinarias de clase, debería perdurar aun cuando pase la situación extraordinaria que vivimos de desescalada ya que el sistema educativo español descansaba en exceso, ya antes de la crisis actual, en recursos externos a la escuela para la realización del refuerzo educativo. Así, según datos de PISA, estamos entre los primeros países de Europa en horas dedicadas a deberes, en estudio con un tutor personal y en clases particulares (Gabaldón-Estevan y Obiol-Francés, 2017). Las horas que el alumnado recibe atención educativa en su centro escolar debería modularse en función de sus necesidades y no depender de la capacidad de las familias para su provisión como ya se hace en otros modelos educativos (Sahlberg, 2014).

\section{Ajustar a las capacidades}

Una de las características que más poderosamente llama la atención en una comparativa europea es que España, al igual que otros países del sur de Europa, presenta cargas lectivas planas por etapa educativa, lo que hace que el alumnado pase el mismo número de horas en el centro escolar desde que inicia su escolarización hasta los 12 años de edad. Por otro lado, en el modelo nórdico y centroeuropeo predomina una carga lectiva generalmente inferior y sobre todo progresiva en función de la edad madurativa del alumnado. Que el alumnado español de 2, 6 y 10 años tengan al día las mismas horas lectivas, distribuidas además generalmente en los mismos intervalos, no responde a criterios pedagógicos ni pediátricos y la reformulación progresiva de las cargas lectivas de acuerdo con la capacidad madurativa del alumnado debería ser una de las primeras cuestiones a considerar en el nuevo modelo (Gabaldón-Estevan y Obiol-Francés, 2017). Una carga lectiva más ajustada a las capacidades de cada grupo de edad facilitaría también la vuelta a las aulas de un mayor número de alumnos durante la desescalada.

\section{Respetar el descanso}

Estudios recientes vinculan el inicio del déficit de descanso con el inicio de la escolarización (Clara y Allen Gomes, 2019). Y está demostrado que tanto la privación de sueño repercute negativamente en el rendimiento escolar (Mullis y col. 2012a, b; Meijer, 2008) del alumnado en general, como que un retraso en la hora de entrada a centro escolar mejora el rendimiento del alumnado adolescente, el más perjudicado por el inicio temprano de la jornada (Kelley y col., 2015). La privación del sueño viene dada por el desajuste entre el reloj interno o biológico de los individuos y las exigencias sociales, como la hora de entrada a la escuela o instituto, es lo que ha venido a denominarse como jet-lag social (Roenneberg, 2012). De manera que una hora de entrada diferente, y progresivamente retardada en función de la edad, se ajustaría mejor a los biorritmos del alumnado facilitando no solo el distanciamiento en tiempo de desescalada sino también el mejor descanso y rendimiento del alumnado al tiempo que se fomentaría un uso más eficiente de las infraestructuras educativas durante y tras la desescalada.

\section{Una alimentación saludable}

La desescalada y el modelo de organización horaria tras la vuelta a la ('nueva') normalidad no puede descuidar la salud del alumnado tampoco en relación con la alimentación. Una de las recomendaciones importantes que se hacen por ejemplo desde la Asociación Valenciana de Pediatría es la referente al horario de comidas, en particular recomiendan realizar la comida del mediodía antes de las 14 horas y de la cena antes de las 21 horas porque de esta manera se tiene menor riesgo de exceso de peso y diabetes, a igualdad de ingesta calórica y de actividad física, teniendo en cuenta además que los "periodos prolongados de ayuno, especialmente en niños pequeños, no son adecuados". Si el alumnado no puede comer en el centro educativo deberá en consecuencia abandonarlo como tarde a las 12:30 para llegar a casa a tiempo de haber comido antes de las 14:00 y si come en el centro como tarde a las 13:00 debería

\footnotetext{
Disponible en https://socvalped.com/noticias/2019/la-jornada-escolar-discontinua-mejora-el-rendimiento-de-los-ninos-y-adolescentes-segun-los-pediatras-valencianos/
} 
incorporarse al comedor. De hecho, en un estudio reciente ${ }^{5}$ mostrábamos que la organización en jornada continua incrementa el lapso temporal entre desayuno y comida, y que el efecto más claro es el retraso de la comida de mediodía en más de una hora. Así la hora media de comida se situaba para el alumnado en jornada partida entre las 13:00 y las 14:00, pero en jornada continua esta se sitúa pasadas las 15:00 de la tarde, en contra la mencionada recomendación pediátrica dado el riesgo de obesidad que supone (Garaulet y Gómez-Abellán, 2014).

\section{Sincronizar la escuela}

La investigación psicológica y bio-psicológica lleva más de un siglo estudiado la interacción entre la hora del día en la que se realizan las tareas y la eficiencia del rendimiento $\mathrm{y}$, hasta la fecha, se ha demostrado que más de 100 funciones humanas varían de acuerdo con el ciclo circadiano (Mayo Clinic, 1995, citado en Klein, 2004). Tanto los estados cognitivos como la vigilancia, la alerta o la atención, como las diversas habilidades, como la coordinación motora, la realización de cálculos simples o las tareas de memoria, son controladas por el reloj biológico de la misma manera que los estados de sueño/vigilia, la temperatura corporal o la circulación de las hormonas. La adaptación a los ciclos circadianos y cronotipos del alumnado demanda una diversificación por edades que hoy en día dista de ser una realidad (Gabaldón-Estevan, 2020). Así, una escuela infantil que plantee estimulación principalmente matutina, con periodos de juego en el exterior y que incluya desayuno, almuerzo, comida, siesta y merienda hasta la recogida por padres y madres parece un planteamiento respetuoso con las necesidades del alumnado. No así un instituto de educación secundaria intensivo y de mañana que para adaptarse a un alumnado adolescente debería concentrar una buena parte de sus sesiones en horario vespertino, retrasando considerablemente el inicio de las clases de la mañana. De hecho, en un estudio reciente se demostraba cómo ubicando los exámenes por la tarde se hacía desaparecer el efecto cronotipo en los resultados académicos (van der Vinne y col., 2015). Por su parte los centros de primaria deberían diversificar también sus franjas horarias en función de la edad de su alumnado, de ser algo más matutino en los primeros cursos a más vespertino al final del ciclo, por lo que, de nuevo, un horario diferenciado será el más apropiado para la desescalada y en adelante.

\section{Una visión holística}

Cada vez es más evidente que la organización del tiempo escolar tiene efectos en la salud y el bienestar del alumnado. A menudo los responsables autonómicos descargan la responsabilidad de decisiones que afectan a la salud de la población infantil y juvenil en la comunidad educativa representada en los consejos escolares de centro que a menudo carecen de la información y la formación necesaria para una la toma de decisión informada y responsable (Fernández-Enguita, 2002). Es por eso que la última recomendación es la inclusión en los consejos escolares de centro de un/a pediatra representante del centro de atención primaria y de un/a trabajador/a social del centro de servicios sociales que corresponda por zona. De esta forma contribuiremos a concebir un sistema educativo con a una visión holística del alumnado, respetuosa y cuidadosa de su salud y su bienestar.

\section{Concluyendo}

No podemos dejar de combatir el desigual acceso a la educación que el COVID-19 ha evidenciado y acrecentado. Concretamente el replanteamiento de los tiempos escolares presenta una oportunidad para una vuelta a la escuela más equitativa al tiempo que reclama el cuestionamiento de inercias y creencias infundadas que debemos desterrar de nuestra organización escolar durante y tras la desescalada. Tratar de retornar a la situación anterior seguirá siendo insuficiente.

\section{Referencias bibliográficas}

Clara, M. I., Allen Gomes, A. (2019). An epidemiological study of sleep-wake timings in school children from 4 to 11 years old: Insights on the sleep phase shift and implications for the school starting times'debate. Sleep Medicine.

Fernández-Enguita, M. (2002) La jornada escolar: propuestas para el debate. Barcelona, Ariel.

Gabaldón Estevan, D. (2020). Horizontes de innovación y transformación de los tiempos escolares. En M. Fernández Enguita (ed.), La organización escolar. Repensar la caja negra para poder salir de ella. Madrid, ANELE-Rede.

Gabaldón-Estevan, D., Obiol-Francés, S. (2017). Guía sobre tiempos escolares. Creativity and Educational Innovation Review 1, 12-69

\footnotetext{
Proyecto TIME: El tiempo en la infancia: un mapeo de España [GV/2019/002].
} 
Gabaldón Estevan, D., Taht, K. (2019). Educación infantil, ideología y clase social. Una lectura al sur de Europa a través de los datos del CIS. Revista de Sociología de la Educación-RASE, 12(3), 367-394.

Garaulet, M., Gómez-Abellán, P. (2014). Timing of food intake and obesity: a novel association. Physiology \& behavior, 134, 44-50.

Kelley, P., Lockley, S. W., Foster, R. G., Kelley, J. (2015). Synchronizing education to adolescent biology: 'let teens sleep, start school later'. Learning, Media and Technology, 40(2), 210-226.

Klein, J. (2004). Planning middle school schedules for improved attention and achievement, Scandinavian Journal of Educational Research, 48:4, 441-450, DOI: 10.1080/0031383042000245825

Meijer, A. M. (2008). Chronic sleep reduction, functioning at school and school achievement in preadolescents. Journal of Sleep Research, 17, 395-405

Mullis, I. V., Martin, M. O., Foy, P., Drucker, K. T. (2012a). PIRLS 2011 International Results in Reading. International Association for the Evaluation of Educational Achievement. Herengracht 487. Amsterdam, 1017 BT, The Netherlands.

Mullis, I. V., Martin, M. O., Foy, P., Arora, A. (2012b). TIMSS 2011 international results in mathematics. International Association for the Evaluation of Educational Achievement. Herengracht 487, Amsterdam, 1017 BT, The Netherlands.

Roenneberg, T. (2012). Internal Time: Chronotypes, Social Jet Lag, and Why You're So Tired. Harvard University Press.

Sahlberg, P. (2014). Finnish lessons 2.0: What can the world learn from educational change in Finland? Teachers College Press van der Vinne, V., Zerbini, G., Siersema, A., Pieper, A., Merrow, M., Hut, R. A., ... Kantermann, T. (2015). Timing of examinations affects school performance differently in early and late chronotypes. Journal of biological rhythms, 30(1), 53-60. 